\section{A EDUCAÇÃO INTEGRAL NO OESTE DO PARÁ: O ESTADO DO CONHECIMENTO A PARTIR DAS DISSERTAÇÕES DO PPGE-UFOPA}

\author{
INTEGRAL EDUCATION IN THE WEST OF PARÁ: THE STATE OF KNOWLEDGE \\ FROM PPGE-UFOPA DISSERTATIONS
}

\author{
Nirlanda Figueiredo da Silva \\ Universidade Federal do Oeste do Pará - Brasil \\ Maria Lilia Imbiriba Sousa Colares \\ Universidade Federal do Oeste do Pará - Brasil
}

Resumo: Este artigo apresenta um estudo desenvolvido a partir das dissertações defendidas na Universidade Federal do Oeste do Pará - UFOPA, no período de 2016 a 2018, no âmbito do Programa de Cooperação Acadêmica (PROCAD). É uma pesquisa de cunho bibliográfico e documental, que por meio das reflexões de Lima e Almada (2013); Cavaliere (2010) e Coelho (2009), fez um contraponto entre as disposições do Programa Mais Educação (PME), do Programa Ensino Médio Inovador (ProEMI) e as concepções apresentadas nas dissertações. Teve como objetivo apresentar as proposições obtidas a partir dos dados estudados nas dissertações. A análise dos textos mostra que, embora haja discussão relacionada à educação integral, ainda existem concepções que não estão de acordo com suas premissas. $\mathrm{O}$ estudo dos autores enfatiza que, embora se tenha obtido avanços, no desenvolvimento intelectual dos alunos, há necessidade de ajustes, sobretudo, no que se refere à concepção do que seja educação integral. O estudo evidenciou também, a importância de se considerar o contexto no qual estão inseridos e que, a região Oeste do Pará contém especificidades como as dificuldades de deslocamento e precariedade na estrutura física das escolas. Tendo em vista esses aspectos, as pesquisas descritas evidenciaram a importância da ampliação do debate sobre educação integral, uma vez que, os envolvidos não têm clareza de suas concepções.

Palavras chave: Educação integral; Estado do conhecimento; Concepções.

\begin{abstract}
This article presents a study developed from the dissertations defended at the Federal University of Western Pará - UFOPA, in the period from 2016 to 2018, within the scope of the Academic Cooperation Program (PROCAD). It is a bibliographic and documentary research, which through the reflections of Lima and Almada (2013); Cavaliere (2010) and Coelho (2009), made a counterpoint between the provisions of the Mais Educação Program (PME), the Innovative High School Program (ProEMI) and the concepts presented in the dissertations. It aimed to present the proposals obtained from the data studied in the dissertations. The analysis of the texts shows that, although there is a discussion related to integral education, there are still conceptions that are not in accordance with its
\end{abstract}


premises. The authors' study emphasizes that, although advances have been made in the intellectual development of students, there is a need for adjustments, especially with regard to the concept of what is integral education. The study also showed the importance of considering the context in which they are inserted and that, the Western region of Pará contains specificities such as the difficulties of displacement and precariousness in the physical structure of schools. In view of these aspects, the research described showed the importance of expanding the debate on comprehensive education, since those involved are not clear about their conceptions.

Keywords: Integral education; State of knowledge; Conceptions.

Resumen: Este artículo presenta un estudio desarrollado a partir de las disertaciones defendidas en la Universidad Federal de Pará Occidental - UFOPA, en el período de 2016 a 2018, dentro del alcance del Programa de Cooperación Académica (PROCAD). Es una investigación bibliográfica y documental, que a través de las reflexiones de Lima y Almada (2013); Cavaliere (2010) y Coelho (2009), hicieron un contrapunto entre las disposiciones del Programa Mais Educação (PME), el Programa innovador de escuela secundaria (ProEMI) y los conceptos presentados en las disertaciones. Su objetivo era presentar las propuestas obtenidas de los datos estudiados en las disertaciones. El análisis de los textos muestra que, aunque una discusión relacionada con la educación integral, todavía hay concepciones que no están de acuerdo con sus premisas. El estudio de los autores enfatiza que, aunque se han hecho avances en el desarrollo intelectual de los estudiantes, existe la necesidad de ajustes, especialmente con respecto al concepto de lo que es la educación integral. El estudio también mostró la importancia de considerar el contexto en el que se insertan y que, la región occidental de Pará contiene especificidades tales como las dificultades de desplazamiento y precariedad en la estructura física de las escuelas. En vista de estos aspectos, la investigación descrita mostró la importancia de expandir el debate sobre la educación integral, ya que los involucrados no tienen claras sus concepciones.

Palabras clave: Educación integral; Estado del conocimiento; Concepciones.

\section{INTRODUÇÃO}

A educação integral tem ganhado destaque nos últimos anos, embora as discussões acerca desta temática remetam à Grécia antiga, período no qual o conceito de educação integral “esteve presente no debate educacional dos filósofos da Grécia antiga, dos representantes do iluminismo, dos marxistas, pragmatistas, construtivistas e pós-modernos, além de outros, com sentidos e significados diversos.” (LIMA, 2013, p. 33).

No final do século XVII, a educação integral estabelecia como uma proposta de "formação do homem completo". No período da Revolução Francesa, sob o controle jacobino, instituindo uma concepção considerando "o ser físico, moral e intelectual de cada estudante, assumindo a escola como um lugar privilegiado do trabalho educativo." (LIMA e ALMADA, 2013, grifos no original).

Este texto foi elaborado a partir da análise das concepções de educação integral apresentadas nas dissertações vinculadas ao Programa de Cooperação Acadêmica - PROCAD, por meio do projeto “As experiências pedagógicas das políticas de educação integral na 
Amazônia: rede de pesquisa e formação", defendidas na Universidade Federal do Oeste do Pará - UFOPA, no período de 2016 a 2018, sendo um estudo de caráter bibliográfico e documental cujo objetivo foi apresentar as proposições extraídas das dissertações analisadas.

Para o desenvolvimento desta pesquisa, consideram-se alguns procedimentos, que segundo Romanowski e Ens (2006) desencadeiam um processo de análise qualitativa do que já se produziu nas diversas áreas do conhecimento. Em um levantamento apresentado por Romanowski (2002), a partir de um estudo feito com base nas teses e dissertações produzidas acerca das licenciaturas no Brasil nos anos 1990, evidenciou-se o caráter analítico e descritivo desse tipo de pesquisa.

Em virtude disso, para a efetivação deste trabalho foi realizado o levantamento das dissertações defendidas no período de 2016 a 2018, nos bancos de dados da biblioteca da UFOPA e no Programa de Pós-graduação em Educação da UFOPA. Em seguida, foi feita a leitura das dissertações sobre educação integral defendidas no período de 2016 a 2018, para a elaboração de uma síntese preliminar, a fim de identificar os temas, os objetivos e as conclusões dos pesquisadores; e por último a análise e elaboração das conclusões a partir das concepções identificadas nas dissertações.

A partir do levantamento previamente realizado, chegou-se ao quantitativo de nove dissertações a serem analisadas. Uma das etapas essenciais para a análise foi a leitura das dissertações, dando ênfase ao resumo num primeiro momento, foi imprescindível para identificação da temática de educação integral, pois o resumo tem a função de sintetizar o que há de mais importante no texto, facilitando, dessa forma, o trabalho de analisar o objeto estudado.

Para a escrita deste texto, escrevemos essa introdução, seguida do conceito de educação integral especificando os programas indutores. Posteriormente, fundamentadas na análise das dissertações estudadas apresentamos as proposições resultantes da pesquisa.

\section{EDUCACAO INTEGRAL E OS PROGRAMAS INDUTORES}

No Brasil, o conceito de Educação Integral está associado a um contexto sócio histórico que vem sendo construído desde o século XX. A respeito do tema, Azevedo et al (2013, p. 49), argumentam que:

Compreender o significado da expressão de "educação integral" requer, primeiramente, a consciência de que não existe hegemonia quanto a sua 
definição, uma vez que ao longo da história, encontram-se diferentes interpretações acerca desta educação ampla para o individuo, com objetivos político-ideológicos distintos. De modo semelhante, para compreender as matizes ideológicas que fundamentam as concepções e práticas de educação integral que se disseminam no Brasil, no decorrer do século XX, torna-se imperioso refletir sob uma perspectiva sócio-histórica.

Sob este prisma, a educação integral, em sua essência, pressupõe a formação integral do ser humano, ou seja, o ensino do português ou da matemática, por exemplo, não deve ser dissociado da educação emocional e da formação para a cidadania. Essa educação não requer obrigatoriamente o tempo integral, embora se acredite que mais tempo amplie as possibilidades de se realizar mais atividades.

No período que compreendeu a segunda metade do século XX, diferentes grupos, de distintos posicionamentos político-ideológicos, debatiam sobre educação integral. Conforme discute Coelho (2009, p. 88), havia um grupo bastante mesclado, por exemplo, católicos, que defendiam uma concepção de educação integral que priorizava atividades intelectuais, físicas, artísticas e ético-religiosas, estavam "aliadas a uma disciplina rigorosa, aos integralistas, aos anarquistas e aos liberais, como Anísio Teixeira, que defendia e implantou instituições públicas escolares, entre as décadas de 30 e 50, em que essa concepção de educação foi praticada.” Em síntese, em termos de concepções destacam-se:

As correntes autoritárias e elitistas a encampavam com o sentido de ampliação do controle social e dos processos de distribuição criteriosa dos indivíduos nos segmentos hierarquizados da sociedade. O extremo dessa tendência expressou-se na concepção de educação integral da Ação Integralista Brasileira. Já as correntes liberais encampavam a educação integral com o objetivo de reconstrução das bases sociais para o desenvolvimento democrático, o qual só poderia se dar a partir de indivíduos intencionalmente formados para a cooperação e a participação. Entre os liberais, destaca-se o nome de Anísio Teixeira, por sua significativa elaboração teórica e técnica, visando à ampliação das funções da escola e o seu fortalecimento como instituição. (CAVALIERE, 2010, p. 249).

A educação integral reaparece nos dias atuais, em virtude de estar expressa nos documentos oficiais, integrando programas instituídos pelo governo, na tentativa de promover melhorias na educação. Contudo, a educação integral defendida nesta pesquisa não é aquela que se debruça apenas para ensino das disciplinas escolares de forma a preparar para o mercado no trabalho, mas a educação que não dissocia o corpo e o intelecto, que considera a formação humana para a emancipação em todos os seus aspectos. 
O Programa Mais Educação (PME) foi instituído pela Portaria Normativa Interministerial $\mathrm{n}^{\circ}$ - 17, de 24 de abril de 2007. No documento oficial infere-se que o programa visa "fomentar a educação integral de crianças, adolescentes e jovens, por meio do apoio a atividades socioeducativas no contra turno escolar (BRASIL, 2007)”. O programa constitui-se como uma política pública, uma vez que atua no sentido de ratificar as determinações da LDB (BRASIL, 1996) e do Estatuto da Criança e do Adolescente (ECA).

O Programa Mais Educação é posto, sobretudo nos documentos oficiais, como uma tentativa de promover essa educação integral por meio da ampliação do tempo escolar com atividades artísticas, culturais e sociais. Trata-se de uma iniciativa para o fomento à educação para o ensino fundamental de nove anos. Ao trazer a questão do contra turno escolar, o PME abre espaço para o diálogo sobre a ampliação do tempo de permanência do aluno na escola, tendo em vista a necessidade de se preparar esse espaço, na tentativa de garantir em nível nacional a efetivação de políticas educacionais.

Ainda no rol dos programas governamentais, o Programa Ensino Médio Inovador (PROEMI), visa propiciar aos jovens uma educação preparatória para o mercado de trabalho, mas também, com atividades que acrescentem conhecimentos variados ao seu repertório cultural. O PROEMI é um marco regulatório direcionado ao ensino médio, com o intuito de fomentar a educação integral nesse nível de ensino. Foi instituído pela portaria $n^{\circ} 971$, de 29 de outubro de 2009 (BRASIL, 2009) e regulamentado pela resolução ${ }^{\circ}$ 31, de 22 de julho de 2013 (BRASIL, 2013). Em suas premissas, o programa busca a melhoria da qualidade do ensino, através de sua expansão, combinando ensino técnico científico à formação geral, inserindo atividades de cunho artístico e cultural para enriquecer a formação de um indivíduo completo. Uma característica em comum entre o PME, o PROEMI é o fato de serem:

[...] programas indutores de educação integral em tempo integral fomentados pelo governo federal. Os dados iniciais nos mostram que a implementação dos programas PME e ProEMI aconteceram de maneira gradual e que nem todas as escolas pertencentes à rede pública estadual no município de Santarém/PA fizeram na época sua adesão voluntária aos programas[...] (GOMES; COLARES, 2019, p. 319).

São programas que propõe ações que objetivam fomentar o desenvolvimento dos alunos por meio da ampliação da jornada escolar, promovendo atividades desenvolvidas nas escolas com vistas a proporcionar ao aluno a obtenção de conhecimentos não apenas no âmbito escolar. Contudo, essa ampliação não garante que se tenha uma educação integral na qual, como discute 
Gadotti (2009), o indivíduo é concebido como um ser completo; o currículo é integrado; há empenho na formação integral do indivíduo em aspectos culturais, éticos, cognitivos, estéticos e políticos. Segundo o autor, essa educação não demanda tempo integral, mas também, não desconsidera a possiblidade de melhor realização com ele.

\section{PROPOSIÇÕES A PARTIR DAS PESQUISAS ANALISADAS}

A partir da leitura das dissertações foi possível verificar que para ter uma concepção de educação integral, faz-se necessário distinguir algumas denominações, que por pertencerem ao mesmo campo semântico, por vezes podem ser tomadas como sinônimas. Nessa perspectiva, Aguiar (2016) aponta a importância de se fazer uma distinção entre os conceitos de educação integral e educação em tempo integral, em virtude da utilização desses vocábulos como sinônimos. A clareza desses termos é fator determinante para entender o funcionamento do PME como política indutora de educação integral, pois o programa representa uma inovação, mas ao mesmo tempo, um grande desafio. Isso se deve aos objetivos propostos pelo programa, que são entre outros:

[...] contribuir para reduzir as desigualdades educacionais através da ampliação de tempos, espaços, oportunidades educativas e compartilhamento da tarefa de educar entre os profissionais da educação e outros segmentos. Acredita-se que a concretização desse propósito requer uma vivência democrática, sem desconsiderar as relações diversificadas que permeiam o espaço educativo e as múltiplas funções da escola. (AGUIAR, 2016, p.76).

É enfatizada a importância da participação de todos para que o PME obtenha os resultados esperados, como o de melhorar a qualidade do ensino na escola pública de ensino fundamental. Por essa razão, a autora ouviu os educadores da escola que estavam envolvidos no PME. Com o auxílio do uso da técnica das entrevistas semiestruturadas, constatou-se que:

A respeito da concepção de educação integral percebe-se que os educadores entrevistados apresentam posicionamentos variados e divergentes. Para alguns (AC2, BD1 e BC2) a "extensão do tempo escolar" é imprescindível para se promover uma educação integral [...] (AGUIAR, 2016, p. 120).

A partir desse posicionamento, infere-se que alguns dos entrevistados consideram que, para que haja educação integral, a ampliação do tempo é determinante, embora os sujeitos da pesquisa compreendam que há distinção entre educação integral e educação em tempo integral.

Com base nos resultados obtidos, a partir dos relatos dos entrevistados, argumenta-se que para que os problemas existentes na escola sejam vencidos, a fim de alcançar a qualidade 
proporcionada pela educação integral, algumas medidas devem ser tomadas, como por exemplo, "oportunizar momentos para formação continuada, planejamento coletivo entre professores, monitores e coordenadores do PME, reelaborar o Projeto Político Pedagógico, mobilizar, incentivar e, fortalecer a participação da comunidade escolar (AGUIAR, 2016, p. 155)”. Para o sucesso do programa, é necessária uma ação coletiva, na qual todos os envolvidos no processo possam participar, cabe ao governo por sua vez, acompanhar desenvolvimento das atividades para verificar o que pode e deve ser melhorado.

Castro (2017) argumenta que as políticas educacionais dão ênfase à ampliação do tempo quando se trata de educação integral e salienta a necessidade de reflexão de qual o sentido dessa ampliação de tempo para o ensino. Segundo a autora, o importante não é oferecer mais tempo na escola e sim proporcionar uma educação integral que viabilize uma formação completa. Em outras palavras:

\begin{abstract}
Para romper com essa visão segmentada de ensino-aprendizagem, é preciso assumir um olhar interdisciplinar, no qual todas as disciplinas devam estar organizadas de modo que haja continuidade entre as temáticas abordadas, e, para que isso ocorra, as secretarias de educação devem promover formações continuadas, trazendo como enfoque principal a interdisciplinaridade. No entanto, é ingênuo imaginar que essa solução resolva todos os problemas de uma educação integral em tempo integral, devido às implicações e demandas que surgem com esse novo modelo de educação, pois os professores e os gestores não são capazes de resolver problemas de ordens sociais e financeiras, tarefa essa das autoridades governamentais competentes. (CASTRO, 2017, p.90).
\end{abstract}

A autora acrescenta, ainda, que devem ser esclarecidas algumas ambiguidades encontradas nos termos "educação integral" e "educação de tempo integral", "extracurricular" e "intracurricular" que segundo a autora apresentam sentido controverso até nos documentos que regulam a educação. Para identificar as ações da Secretaria Municipal de Educação (SEMED) do município de Santarém, Ferreira (2016) amparou-se na pesquisa histórica e documental, para embasar a discussão acerca de educação integral e ampliação do tempo escolar, a partir das categorias currículo, perfil dos professores, infraestrutura e financiamento. Dentre as ações promovidas pela SEMED, foi identificado que:

[...] a criação de duas escolas de tempo integral não faz parte de uma proposta específica de educação integral articulada por um plano municipal de ampliação de tempo escolar. Cada uma dessas iniciativas também não repercutiu em formação docente de preparação para esta realidade, nem na progressiva ampliação da carga horária do professor, articulada por um plano de carreira, que lhe oportunize uma dedicação exclusiva para a escola de tempo integral. Ou seja, apesar do alargamento progressivo do tempo escolar 
nas escolas municipais de Santarém, a Secretaria ainda não consolidou uma política de formação de seus profissionais para esta realidade, como, por exemplo, um plano de carreira que lhe permita mais segurança no desenvolvimento de sua profissão. (FERREIRA, 2016, p.150).

Houve a criação das escolas, porém, esta ação não foi articulada para a efetivação de uma educação integral, tendo em vista que, mesmo a formação continuada oferecida aos docentes, não culminou na integração entre as disciplinas e as oficinas do PME. Outro fato relacionado aos professores é a instabilidade do quadro profissional, tendo em vista a existência de profissionais contratados, fato que provoca descontinuidade do trabalho pedagógico, uma vez que a mudança desses profissionais é contínua.

Com relação à infraestrutura, detectou-se que os espaços reduzidos e as altas temperaturas evidenciam o desconforto para alunos e professores. No que diz respeito à gestão financeira, a autora demonstrou preocupação ao verificar que embora não sejam utilizados da forma adequada, os recursos existe, "talvez pela complexidade da máquina administrativa e alguns arranjos locais, os recursos não sejam tão bem aproveitados como deveriam ser. Instituise um valor mínimo por aluno/ano em todo o território nacional” (FERREIRA, 2016, p.152).

Considerando os resultados elencados na pesquisa, concluiu-se que não se pode considerar como políticas o que a SEMED desenvolveu para fomentar a educação integral, tendo em vista a descontinuidade em virtude da troca de governo. Ainda sobre os programas indutores de educação integral, tem-se a pesquisa desenvolvida por Gomes (2017) que lançou mão da pesquisa bibliográfica, documental e empírica e como técnica de coleta de dados, a entrevista semiestruturada para analisar o Programa Ensino Médio Inovador (PROEMI) como política indutora de educação integral em uma escola da rede estadual de Santarém, Pará.

O estudo demonstrou que mesmo depois de três anos de efetivação do programa na escola observada, a maioria dos membros da escola que participa do PROEMI ainda trata educação integral e educação em tempo integral como vocábulos sinônimos, associando a educação integral à ampliação do tempo para atividades extraclasse como música, arte e esporte.

Houve uma formulação sólida no que concerne ao referencial teórico que embasa o programa, porém, isso não foi a garantia de uma sequência na elaboração e implementação coerente com o que foi planejado. A partir da fala dos entrevistados, Gomes constatou que:

[...] os documentos oficiais que expressam a concepção do programa não correspondem de fato ao processo de implantação que aconteceu na Escola Estadual Mocoronga, onde muitas etapas como: a formação inicial e contínua assumidas no estado do Pará pelo IU, sobre o ProEMI, bem como o PJF, não 
foram seguidas de acordo com o planejado. O acompanhamento e monitoramento pela Seduc, que em Santarém é representada pela $5^{\mathrm{a}}$ URE, não foi satisfatório no sentido de assessoramento à escola quanto às dúvidas e prazos estabelecidos pelo Comitê Estadual do Programa. (GOMES, 2017, p.145).

A falta de conhecimento técnico para a inserção dos dados nas plataformas específicas e a não participação docente nos projetos interdisciplinares, foram situações que ocasionaram a adaptação do programa às condições da escola. Em relação às ações pedagógicas desenvolvidas no PROEMI, as orientações sobre a efetivação do programa, não estão de acordo com realidade encontrada na implantação, no que diz respeito a questões relativas ao assessoramento técnico, pedagógico e financeiro; à garantia de execução dos projetos originados na demanda da comunidade escolar; à obrigatoriedade em compreender a coexistência do PROEMI e o Projeto Jovem do Futuro em suas concepções e metodologias distintas; e à necessidade de organização pedagógica da escola em turno parcial para atender propostas de um currículo interdisciplinar.

Para que essas falhas sejam superadas, deve haver a participação da comunidade escolar na tomada de decisões no que se refere ao trabalho pedagógico, ou seja, o envolvimento é fundamental para que as políticas educacionais se materializem em resultados positivos nas escolas. Outros pontos importantes destacados por Gomes (2017) é a concepção de educação integral e tempo integral defendida pela comunidade escolar, a discussão das decisões do programa, a formação docente, bem como as condições de trabalho, o tempo e o espaço disponível para que se organize e desenvolvam atividades de cunho interdisciplinar para que a educação seja uma realidade na escola.

A partir da pesquisa desenvolvida com vistas a compreender as concepções dos gestores de escolas, Silva (2016), ao investigar os precedentes do PME como política indutora de educação integral, constata que os dados oficiais disponibilizados em âmbito nacional são estatísticos, ou seja, de cunho quantitativo, e não possibilitam mensurar como a educação se materializa nas escolas e, principalmente, se a ampliação dos espaços educativos converge para uma formação integral. Para suprir essa necessidade, a autora buscou as bases teóricometodológicas do PME e verificou-se que, embora alicerçado em teorias diversas, o programa é fortemente influenciado pelas experiências de Anísio Teixeira que relacionam a educação integral com a ampliação do tempo escolar. Nestes termos, a autora argumenta que:

Desta forma, compreender a concepção de Educação Integral de tempo integral, presente no Programa Mais Educação, implica, considerar estes elementos, com referência à ampliação da jornada escolar, e espaço, aos 
territórios em que cada escola está situada. Implica ainda considerar a oferta dos serviços públicos requeridos para formação integral o que pressupõe políticas e ações integradas (intersetoriais) que considerem, além da educação, outras demandas dos sujeitos, articuladas entre os campos da educação, do desenvolvimento social, da saúde, do esporte, da inclusão digital e da cultura. (SILVA, 2016, p.88).

Diante do exposto, associa-se à educação integral a termos como: ampliação do tempo; ações socioeducativas; espaço educativo; intersetorialidade; e educação integral, de acordo com o que está disposto nos documentos oficiais. No entanto, o que se percebe é que:

[...] a leitura dos documentos balizadores do Programa Mais Educação revela a indeterminação do que seria a "formação integral" do educando ao mesmo tempo em que apontam para a responsabilização da comunidade escolar em um claro movimento de omissão do Estado no provimento de recursos necessários. (GOMES, 2018, p. 84).

Com base nos resultados da pesquisa que buscou analisar as concepções de educação integral, Siqueira (2016) infere que o PME insere-se na concepção de educação integral baseada na vertente Liberal-Pragmatista. Nestes termos:

O Programa Mais Educação, conforme indicado nos documentos publicados pelo MEC, se insere nessa proposta pela ênfase dada à noção de aprendizagem, através do meio, ou seja, através de vivências; e a ênfase no "aprender a aprender" que dá mais valor ao processo do que ao produto. Atuando em conformidade com a lógica do capitalismo e liberalismo que reproduzem as desigualdades e os antagonismos entre as classes sociais, essa visão educativa não problematiza o papel do Estado na garantia e regulação da educação pública. (SIQUEIRA, 2016, p.126).

A autora não identificou na fala dos sujeitos uma concepção clara do que seja educação integral, além disso, observou-se também, o desconhecimento sobre os fundamentos teóricos que orientam o Programa Mais Educação. Segundo Siqueira (2016, p.127) “O percurso entre a concepção das propostas e a implementação na instituição escolar, sofreu variações, seja pelas condições locais, seja pelo pouco conhecimento das diretrizes que nortearam esse programa".

A presença da vertente assistencialista também ficou evidenciada na pesquisa de Siqueira (2016), o que reforça, o duplo papel da escola do "proteger e educar". A ênfase nas oficinas de letramento valida a preocupação com o ensino da Língua Portuguesa, assim como também há o destaque para a matemática, em prejuízo a outros aspectos da formação humana.

A autora aponta como fator importante à participação da comunidade escolar no cotidiano da escola. Essa participação se dinamizou com o advento do PME. A participação é um ponto determinante para uma gestão democrática. A gestão da escola deve, portanto, abrir 
espaço para a comunidade para que se construa uma proposta educativa para a formação do ser humano em sua completude (SIQUEIRA, 2016).

Ao analisar o processo de implementação do PME, Vasconcelos (2016) destaca que a forma como se deu a efetivação do programa, segundo a autora, "aligeirada" foi prejudicial, o que vai de encontro com o que está posto nos documentos oficiais, nos quais se identificou que:

A proposta que emerge da implementação do tempo integral nas escolas do campo visa qualificar os tempos e os espaços, de forma especifica não mitigando os saberes e as vivencias desses povos. As oportunidades educativas devem ser pensadas e articuladas em conjunto com a comunidade, igreja, sindicatos, na intenção de ampliar o território educativo da escola para fora da escola, dessa maneira dá-se espaço para que a educação integral não seja vista apenas como horizonte, mas como realidade. (VASCONCELOS, 2016, p.49).

A educação integral será possível somente se houver a participação de todos os envolvidos no processo, para isso, o diálogo permanente é necessário, a fim que haja planejamento e consenso na tomada de decisões. O acompanhamento também é considerado essencial para a pesquisadora, tendo em vista que o tipo de formação dado aos monitores é fator preponderante para o bom andamento do programa, tendo em vista a necessidade de uma base teórica sólida. Entretanto, o que foi constato foi a falta de qualificação dispensada aos profissionais, fato que pressupõe a insucesso das atividades, segundo aponta a avaliação dos próprios professores participantes do PME.

A autora conclui, portanto, que o modelo de política pública direcionado pelo Estado ao formular as políticas educacionais, com uma fundamentação com base em documentos de cunho político e também pedagógico é importante, contudo, no momento da implementação do programa, há uma desconstrução dessas políticas, em virtude de problemas financeiros que influenciam diretamente as questões estruturais e pedagógicas, ocasionando a improvisação na efetivação do programa.

Vasconcelos (2017), a partir dos resultados relacionados à formação dos professores, evidenciou o contato superficial no que concerne ao trabalho pedagógico, em virtude de trabalharem em tempo integral e necessitam trocar experiências, para a autora:

[...] para os professores das escolas de tempo integral é necessária uma contínua formação para que possam discutir os desafios e compartilhar práticas e ações de educação integral, na qual as relações individuais se transformem em relações coletivas. Evidenciamos que os professores da escola Frei Fabiano possuem um contato superficial em relação ao trabalho pedagógico, pois os docentes da manhã e da tarde só tem a oportunidade de 
estarem juntos apenas nas reuniões pedagógicas não tendo um tempo maior para dialogarem entre si. (VASCONCELOS, 2017, p.45).

A autora argumenta que se faz necessário um esforço contínuo por parte da Secretaria de educação para se estabelecer um programa de formação continuada que seja permanente e que possa envolver não somente professores, como também toda a comunidade escolar, para que se possa discutir sobre educação integral, considerando a falta de conhecimento sobre o seu conceito. Essa formação deve funcionar no sentido de trocar informações para que se possa desenvolver soluções a partir das experiências e dificuldades de cada participante do processo educativo.

Ainda sobre o fomento do processo do ensino aprendizagem para a educação integral, Pereira (2018) destaca que a biblioteca escolar tem uma função de destaque nesse processo. Porém, as pesquisas realizadas pelo autor demonstram um descompasso entre as ações previstas nos documentos oficiais e o que se observa no cotidiano na escola. Para o autor,

[...] convém destacar que se observa uma enorme ausência de sintonia entre as disposições constantes de leis e planos e a biblioteca escolar, merecendo uma observação: mesmo que seja importante e necessária a previsão legal ou documental, será preciso uma intermediação no nível operacional no sentido de se fazer cumprir o previsto nos documentos. (PEREIRA, 2018, p.112).

Em resumo, pode-se inferir que a biblioteca escolar auxilia no processo de ensino aprendizagem do aluno, contudo, ela deve ser usada como um elemento estratégico. $\mathrm{O}$ fato de existir uma biblioteca na escola não garante que ela cumpra o seu papel no processo educativo. Esse espaço deveria estar inserido nas atividades propostas aos alunos para que se chegue a uma educação para a formação integral.

\section{CONSIDERAÇÕES FINAIS}

A educação integral é uma discussão que remonta à antiguidade, à paideia grega, na qual se preconizava uma formação completa do homem. No Brasil, a educação integral tomou forma a partir das experiências de Anísio Teixeira, na Bahia, nos anos 1950 e de Darcy Ribeiro no Rio de Janeiro na década de 1980. Apesar disso, a educação integral ainda é um tema desconhecido em sua essência, o que faz com que ela seja confundida com o tempo integral, dada à existência dos programas indutores de educação integral cuja ênfase é o tempo integral. Para esclarecer esses pontos, este estudo fez uma análise das concepções de educação integral nas produções acadêmicas do PPGE da UFOPA de 2016 a 2018. 
A partir das análises contida nas dissertações, o PME mostrou-se uma política pública de cunho social, tendo em vista que presta atendimento à população menos favorecida economicamente, sobretudo, àqueles alunos com baixo rendimento escolar, na tentativa de diminuir a situação de exclusão social. Por isso, o programa incorporou nas suas atividades, a participação da família, da comunidade e da iniciativa privada, fato que confirma a tentativa de inclusão social.

No que diz respeito à visão das autoras das dissertações a respeito do programa, inferiuse que a proposta de educação integral do PME está diretamente ligada à ampliação da jornada escolar em razão existência do contra turno escolar. Essa vertente da educação integral está diretamente ligada à corrente pragmatista, na qual o indivíduo aprende pela experiência, que as atividades na escola devem preparar para a vida em sociedade. Além desse caráter prático, ficou evidenciado o teor assistencialista do programa, em virtude da proteção social propagada ao estipular como critério de seleção os alunos em vulnerabilidade social.

Outro programa que ganhou destaque foi o PROEMI, direcionado ao ensino médio com o objetivo de oferecer ao jovem uma formação voltada não só para o trabalho, mas também para o conhecimento de outras instâncias do conhecimento, através da ampliação das atividades por meio do redesenho curricular. Contudo, a falta de acompanhamento dos responsáveis por fiscalizar o programa foi apontada como um dos fatores que prejudicou o bom andamento do programa, tendo em vista que a efetivação do programa, bem como sua avaliação depende de relatórios e inserção de informações no sistema, o que requer preparação técnica. Em razão da falta de acompanhamento, não houve também as avaliações externas.

Considerando que o PME e o PROEMI foram duas políticas de fomento à educação integral que se destacaram na região Oeste do estado do Pará, cabe aqui ressaltar algumas lacunas identificadas em sua implementação o que ocasionou a descontextualização daquilo que está expresso nos documentos oficiais norteadores dos programas, sobretudo, no que tange à concepção de educação integral.

Uma das observações evidenciadas foi o fato de que o PME e o PROEMI não fez parte de um plano municipal ou estadual, o que evidentemente, viabilizaria a elaboração de um programa apto a suprir as necessidades educacionais da região, considerando a infraestrutura das escolas para a execução das atividades e as condições climáticas da região que suscitam de ambientes climatizados para a realização práticas pedagógicas.

Outro fator determinante para efetivação da educação integral a partir dos programas indutores é a formação continuada. Umas das dificuldades apontadas foi a formação precária e 
superficial do professor, fato que influencia no aprendizado do aluno. Em virtude do caráter participativo, a formação dos professores também necessita de uma integração, na qual os docentes possam receber uma formação teórica a respeito da educação integral, bem como possa compartilhar conhecimentos com os colegas para oferecer um ensino condizente com o que os programas propõem.

Essas dificuldades culminam para a reflexão de que a falta de clareza sobre o sentido da educação integral influencia diretamente nas práticas dos envolvidos no processo educativo, uma vez que não foi percebida uma visão que não fosse influenciada pelo que dizem os documentos norteadores das políticas, ora discutidas. É preciso ter bem definida essa concepção para que seja possível o desenvolvimento de uma educação transformadora. O que se observou, no entanto, a partir das reflexões das autoras, foi a associação do conceito de educação integral ao que as políticas indutoras apregoam, uma educação voltada para o utilitarismo, que menciona a formação atrelada ao capitalismo. O caráter assistencialista assumido pelos programas materializa-se na figura da escola como protetora. Agora não é sua função somente educar, isso evidencia que as políticas educacionais assumem uma função social.

Ficou evidenciada a partir dessas reflexões, a necessidade de se ampliar as discussões sobre educação integral mesmo que o tema não seja recente, considerando que as pesquisas evidenciaram a falta de conhecimento sobre o sentido da educação integral, associando-a, na maioria das vezes ao tempo integral, sobretudo por influência do PME e do PROEMI, cuja ampliação do tempo de permanência do aluno, apresenta-se como uma das principais prerrogativas.

As pesquisas aqui analisadas correspondem ao início das reflexões sobre educação integral na região Oeste do Pará. Elas se tornam extremamente relevantes, por apresentarem informações específicas da região frente às discussões em nível nacional. Pode-se então afirmar que o PROCAD foi de fundamental importância, no sentido de fomentar essas pesquisas, possibilitando o intercâmbio de conhecimentos entre discentes e docentes da região norte e sudeste, ampliando a compreensão sobre a temática da educação integral.

\section{REFERÊNCIAS}

AGUIAR, Maria Sousa. Educação em tempo integral: estudo da trajetória do Programa Mais Educação (PME) nas escolas estaduais de Santarém - PA no período de 2009 a 2015. 173 f. Dissertação de Mestrado. Universidade Federal do Oeste do Pará, Santarém. 2016. 
BRASIL. Ministério da Educação. Portaria Normativa Interministerial $\mathbf{n}^{\circ}$ 17, de 24 de abril de 2007. Institui o Programa Mais Educação. Brasília, DF, 2007.

BRASIL. Ministério da Educação e Cultura - Portaria n 971, de 09 de outubro de 2009. Disponível em: http://portal.mec.gov.br/docman/documentos-pdf/1634-port-971/file//. Acesso em: 01 Maio 2019.

CASTRO, Adriangela Silva de. A Educação Integral em Tempo Integral na Perspectiva da Equipe Gestora: a Realidade de Uma Escola Municipal de Santarém/PA. 2017. 102 fls. Dissertação de Mestrado. Universidade Federal do Oeste do Pará, Santarém, 2017.

CAVALIERE, Ana Maria. Anísio Teixeira e a educação integral. Paidéia (Ribeirão Preto), vol. 20, n. 46, maio-gosto, pp.249-259, 2010.

COELHO, Lígia Martha Coimbra da Costa. História(s) da educação integral. Revista Em Aberto, Brasília, v. 22, n. 80, p.83-96, abr. 2009.

FERREIRA, Gerusa Vidal. Educação de tempo integral em Santarém: Ações da Secretaria Municipal de Educação no período de 2008 a 2014. 173 f. Dissertação de Mestrado. Universidade Federal do Oeste do Pará, Santarém, 2015.

GOMES, Tânia Castro. A Educação Integral e o Programa Ensino Médio Inovador PROEMI: Singularidades desta Política em uma Escola Estadual. 163fls. 2017. Dissertação (Mestrado Acadêmico em Educação) - Universidade Federal do Oeste do Pará, Santarém - PA. 2017.

GOMES, Tânia Castro. Colares, Maria Lília Imbiriba Sousa. A política de educação integral em tempo integral: aperspectiva dos professores. Revista Práxis Educacional, Vitória da Conquista - Bahia - Brasil, v. 15, n. 31, p. 313-332, jan./mar. 2019.

GOMES, Marco Antônio de Oliveira. O Programa Mais Educação em Maringá: apontamentos iniciais da proposta burguesa de educação integral. Revista Exitus, Santarém/PA, Vol. 8, № 3, p. 58 - 86, SET/DEZ 2018.

LIMA, Lucinete Marques. Educação Integral: confrontos filosóficos e reconhecimento político. In: Educação integral: Ideário Pedagógico, políticas e Práticas. LIMA, Francisca das Chagas Silva et al (orgs.). EDUFMA, São Luís, 2013.

PEREIRA, Raimundo Solano Lira. O lugar da biblioteca na escola de tempo integral em Santarém/PA. 144 f. Dissertação de Mestrado. Dissertação de Mestrado. Universidade Federal do Oeste do Pará, Santarém - PA, 2018.

ROMANOWSKI, Joana Paulin. As licenciaturas no Brasil: um balanço das teses e dissertações dos anos 90. Tese (Doutorado) - Faculdade de Educação da Universidade de São Paulo, São Paulo, 2002. 
ROMANOWSKI, Paulin Joana; ENS, Romilda Teodora. As pesquisas denominadas do tipo "estado da arte" em educação. Revista Diálogo Educacional, Curitiba, v. 6, n.19, p.37-50, set./dez. 2006.

SIQUEIRA. Adriana Oliveira dos Santos. O Programa Mais Educação: Concepções e desafios para a gestão escolar. 153 f. Dissertação de Mestrado. Universidade Federal do Oeste do Pará, Santarém, 2016.

SILVA, Luciene Maria. Educação Integral de Tempo Integral: a Concepção dos Sujeitos Participantes do Programa Mais Educação no Município de Oriximiná - Pará. 199 f. Dissertação de Mestrado. Universidade Federal do Oeste do Pará, Santarém, 2016.

VASCONCELOS, Clênya Ruth Alves. As Experiências Pedagógicas da Implementação da Política de Educação em Tempo Integral nas Escolas de Campo na Amazônia Paraense. 2016. 106 fls. Dissertação (Mestrado Acadêmico em Educação) - Universidade Federal do Oeste do Pará, Santarém - PA. 2016.

VASCONCELOS. Milka Oliveira de. A Formação Continuada de Professores na Perspectiva da Política de Educação Integral No Município De Santarém - Pará. 2017. 159 fls. Dissertação de Mestrado. Universidade Federal do Oeste do Pará, Santarém, 2017.

\section{SOBRE AS AUTORAS:}

\section{Nirlanda Figueiredo da Silva}

Mestra em Educação pela Universidade Federal do Oeste do Pará (UFOPA); Membro do Grupo de Estudos e Pesquisas "História, Sociedade e Educação no Brasil". E-mail: nirlandastm@hotmail.com

(iD) http://orcid.org/0000-0002-4152-0649

\section{Maria Lília Imbiriba Sousa Colares}

Doutora e Pós-doutora em Educação pela Universidade Estadual de Campinas (UNICAMP). Docente do Programa de Pós-graduação da Universidade Federa do Oeste do Pará (UFOPA); Líder Adjunta do Grupo de Estudos e Pesquisas "História, Sociedade e Educação no Brasil"; Bolsista de Produtividade em Pesquisa/CNPq Nível 2. E-mail: maria.colares@ufopa.edu.br

(iD http://orcid.org/0000-0002-5915-6742 